\title{
The Ferrara thrust earthquakes of May-June 2012: preliminary site response analysis at the sites of the OGS temporary network
}

\author{
Enrico Priolo ${ }^{1,}$, Marco Romanelli ${ }^{1}$, Carla Barnaba ${ }^{1}$, Marco Mucciarelli ${ }^{1,2}$, Giovanna Laurenzano ${ }^{1}$, \\ Lorella Dall'Olio ${ }^{3}$, Nasser Abu Zeid ${ }^{4}$, Riccardo Caputo ${ }^{4}$, Giovanni Santarato ${ }^{4}$, Luigi Vignola ${ }^{5}$, \\ Carmine Lizza ${ }^{5}$, Paolo Di Bartolomeo ${ }^{1}$
}

\author{
${ }^{1}$ Istituto Nazionale di Oceanografia e di Geofisica Sperimentale (OGS), Centro di Ricerche Sismologiche (CRS), Udine and Trieste, Italy \\ ${ }^{2}$ Università della Basilicata, Dipartimento di Strutture, Geotecnica, Geologia Applicata all'Ingegneria (DiSGG), Potenza, Italy \\ ${ }^{3}$ Comune di Ferrara, Servizio Ambiente, Ferrara, Italy \\ ${ }^{4}$ Università di Ferrara, Dipartimento di Fisica e Scienze della Terra, Ferrara, Italy \\ ${ }^{5}$ MALLET s.r.l., Marsicovetere (Potenza), Italy
}

\section{Article history}

Received July 27, 2012; accepted August 27, 2012.

Subject classification:

Surveys, measurements and monitoring, Ground motion, Emilia earthquake, Seismic monitoring, Seismic site response.

\section{Introduction}

Following the $\mathrm{M}_{\mathrm{L}} 5.9$ earthquake that struck the Emilia area in northern Italy on May 20, 2012, at 02:03:53 UTC, and in co-operation with the personnel of the Municipality of Ferrara and the University of Ferrara, a team of seismologists of the Istituto Nazionale di Oceanografia e Geofisica Sperimentale (OGS; National Institute of Oceanography and Experimental Geophysics) deployed a temporary seismographic network. This consisted of eight portable seismological stations, to record the local earthquakes that occurred during the seismic sequence. The OGS intervention was integrated into the broader action of the emergency response to the earthquake sequence, which was promoted by the National Department of Civil Protection and the Istituto Nazionale di Geofisica e Vulcanologia (INGV; National Institute of Geophysics and Volcanology) [Moretti et al. 2012, this volume]. The aim of the OGS intervention was on the one hand to extend the seismic monitoring area towards the East, to include Ferrara and its surroundings, to be ready in case of migration of the seismicity in that direction, and on the other hand to evaluate the seismic response at the instrumented sites.

Some days later, another team of researchers coordinated by the University of Potenza carried out some investigations at a number of sites, and in particular at three of the sites instrumented by the OGS temporary network. These investigations consisted of passive seismic noise measurements: 1) recorded by single stations and processed by the horizontal to vertical (H/V) spectral ratio (HVSR) method; and 2) recorded by arrays and processed by the extended spatial autocorrelation (ESAC) method [Okada et al. 1987, Ohori et al. 2002].
In this report, we first describe in outline the seismic sequence and the geological framework of the area. Then, we describe the OGS temporary network that was deployed. Finally, we show the results obtained in the seismic noise analysis and the three ESAC surveys at these sites, and discuss them in the light of the information available to date on the geological structure of the area.

\section{Outline of the seismic sequence and the geology of the area}

On May 20, 2012, at 02:03:53 UTC, the area of Emilia, which is located in northern Italy, was struck by an earthquake of magnitude $M_{L} 5.9$, with the epicenter at few kilometers from the towns of Mirandola, Finale dell'Emilia and Bondeno, and about $30 \mathrm{~km}$ west of the city of Ferrara (Figure 1). The main earthquake sequence was followed by a new sequence of strong earthquakes nine days later, i.e., on May 29, 2012, the most relevant of which was the $M_{L} 5.8$ earthquake that occurred at 07:00:03 UTC and was located nearly $12 \mathrm{~km}$ WSW of the main event.

The seismic sequence involved the frontal sector of the northern Apennines, and in particular the buried front of the Romagna and Ferrara northward-verging active thrust belt (Figure 1). The frontal-most sector of the northern Apennines is represented by a fold-and-thrust belt that underlies the Po Plain and is buried by a thick wedge-like PlioceneQuaternary depositional succession. Due to the overall geodynamic conditions, subsidence prevails on the locally growing anticlines, therefore generating a laterally variable sedimentary thickness with a depth to bedrock that varies from between a few hundred meters and several kilometers 


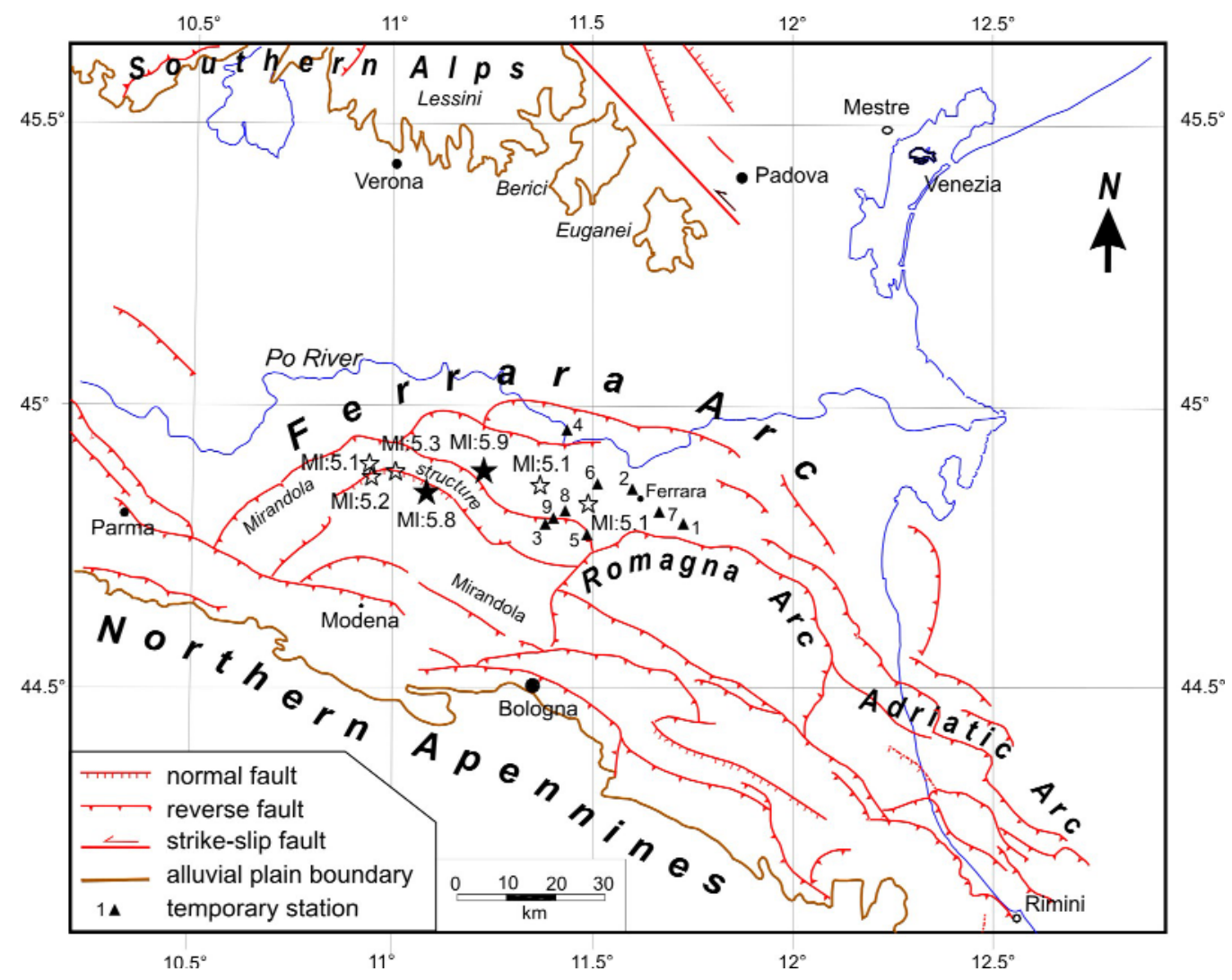

Figure 1. Simplified structural map of the eastern sector of the Po Plain, showing the major Ferrara Arc and the two minor Adriatic and Romagna Arcs. Triangles, OGS temporary seismographic stations installed around Ferrara following the earthquake sequence that started on May 20, 2012. Stars, events of the sequence with $M_{L} \geq 5$ (modified after [Pieri and Groppi 1981] and [CNR-PFG 1991]).
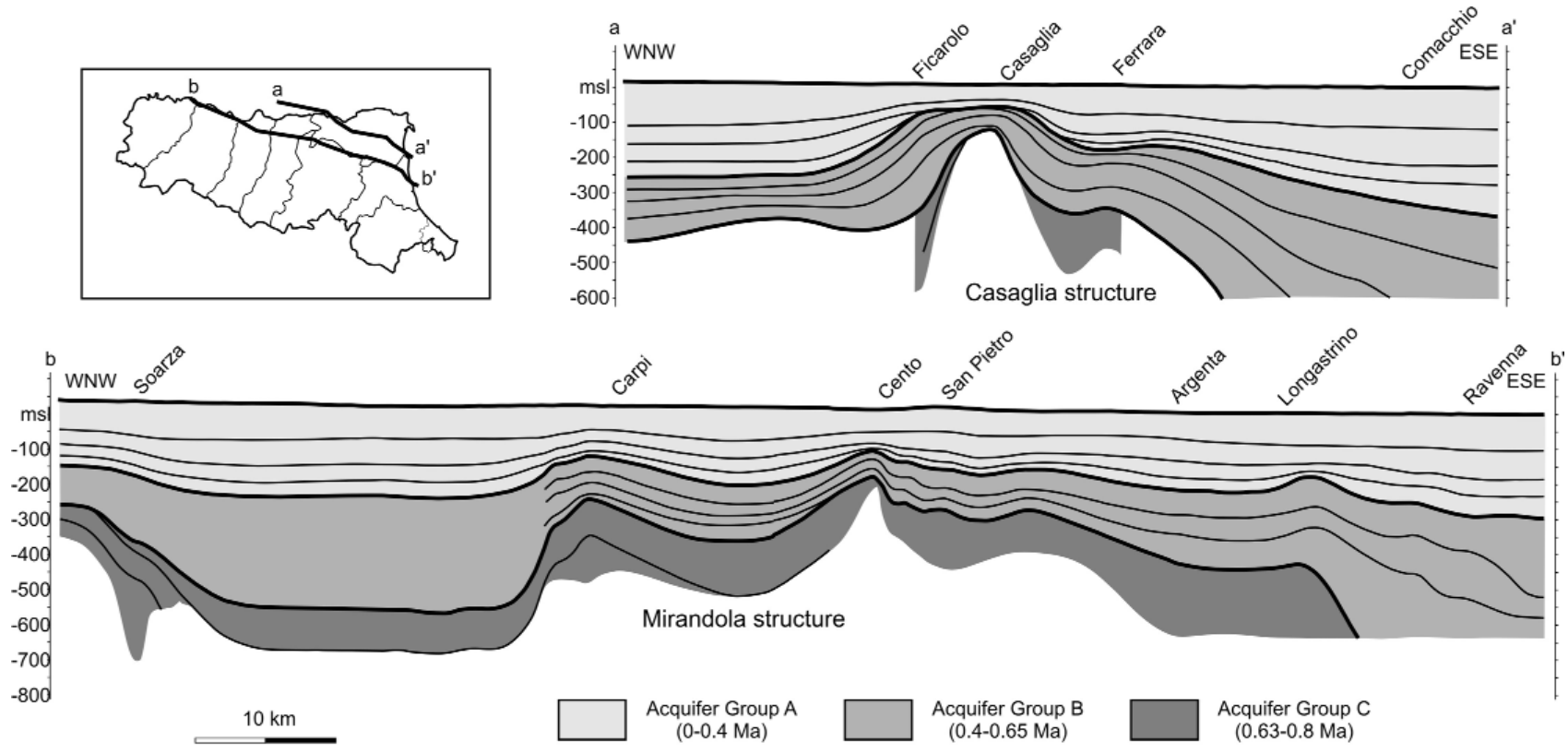

Figure 2. Hydro-geological sections running in the WNW-ESE direction, through (a-a') the Casaglia structure (Ferrara); and (b-b') the Mirandola structure (Modena) (modified after Pieri and Groppi [1981]). Both sections show the main aquifer bodies corresponding to the Middle-Upper Quaternary lithostratigraphic units that mainly consist of alluvial and shallow-water marine deposits that progressively infilled the Po River foreland basin (modified after Regione Emilia-Romagna and ENI-AGIP [1998]).

(Figure 2). The geometry of this hidden chain has been relatively well defined by numerous seismic reflection profiles. The most important tectonic structures are represented by the Ferrara Arc and the minor Adriatic and Romagna Arcs (Figure 1). Recently, Toscani et. al. [2009] showed that some of these blind thrusts are probably still active. 


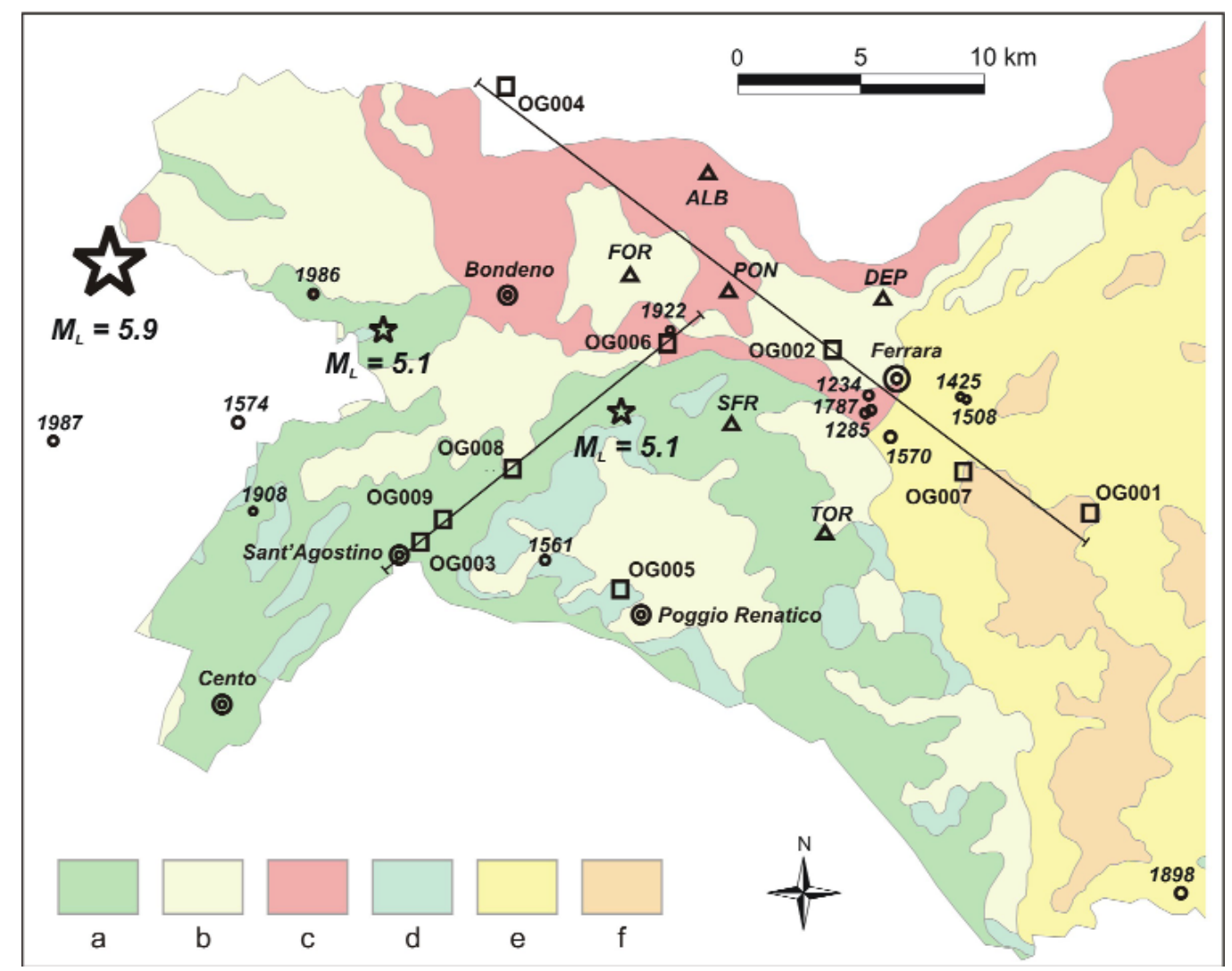

Figure 3. Simplified geological map of the western portion of the Ferrara Province showing the locations of the OGS temporary stations (squares), the permanent stations (triangles) of the local microseismic network of the Ferrara Municipality that is managed by Ferrara University (http:/ / servizi. comune.fe.it/index.phtml?id=2593). Stars, principal shocks of May 20, 2012. Legend of stratigraphic units: (a) medium to fine sand (channel and proximal levee deposits); (b) silty clay, clay and clayey silt (interfluvial and swamp deposits); (c) sandy silt, fine sand and silty clay (distal levee deposits); (d) medium-to-coarse-grained sand (alluvial plain and meander deposits); (e) medium to fine sand (distribution channels and levee deposits); and (f) silt, clayey silt (swamp deposits). The age of the outcropping sediments is Holocene everywhere. Modified after Banca Dati Regione Emilia-Romagna (http://geo.regione.emilia-romagna.it/geocatalogo/).

For the superficial geology of the area where the temporary seismographic network was installed, the outcropping materials are represented by alluvial deposits of different environments, like channels and proximal levees, and inter-fluvial, meander and swamp deposits (Figure 3). As a consequence, the outcropping deposits are Holocene in age and everywhere they are substantially loose or poorly compacted in the first meters to decameters, and granulometrically they vary from clay to coarse sand.

Two preliminary reports prepared by the National Department of Civil Protection in collaboration with other Institutes describe the data recorded by the national accelerometric network and complemented by additional data recorded by a number of temporary stations [Dolce et al. 2012a, b]. These reports bear witness to the strong ground-motion values with an acceleration peak of about $0.9 \mathrm{~g}$ in the vertical component that was recorded during the $\mathrm{M}_{\mathrm{L}} 5.8$ earthquake of May 29, 2012, by the Mirandola station, which was located about $2 \mathrm{~km}$ from the epicenter. The analysis of the seismic noise recorded at some of the stations shows a relatively pronounced peak of the HVSR in the frequency range of $0.6 \mathrm{~Hz}$ to $0.9 \mathrm{~Hz}$, common to all stations. Finally, strong evidence of liquefaction phenomena were reported at several sites (e.g., San Carlo, Sant'Agostino and Mirabello), most of which were attributed to the occurrence of saturated sandy layer(s) at shallow depths deposited along an abandoned reach of the Reno River [Papathanassiou et al. 2012, this volume].

\section{The OGS temporary network and passive-noise measurements}

The OGS temporary network consisted of eight stations that were deployed on May 21, 2012, the day after the mainshock. A ninth site (OG009) was set-up one month later, on June 25, 2012, as a replacement for station OG003, the location of which was no longer available. The removal of the stations was programmed for the end of July 2012. Details on the sites and the instruments used are given in Table 1, while their locations are shown in Figures 1 and 3. All of the stations were set at sampling rates of $125 \mathrm{~Hz}$, and they recorded data in continuous mode on temporary memory. None of the stations were equipped with data-transmission devices.

The locations for the temporary stations were chosen in the area surrounding the city of Ferrara (Figures 1 and 3, Table 1). Detailed information on the temporary network 


\begin{tabular}{cccccccc}
\hline Code & Sito & $\begin{array}{c}\text { Epicentral } \\
\text { distance }(\mathbf{k m})\end{array}$ & $\begin{array}{c}\text { Start } \\
\text { Recording }\end{array}$ & Lat & Lon & Acquisition Unit & Sensor \\
\hline OG001 & Cona - Ospedale Nuovo & 40.9 & $2012 / 05 / 25$ & 44.78921 & 11.727598 & Nanometrics Orion & Lennartz 1s 3D Light \\
OG002 & Comune di Ferrara - Lavori Pubblici & 29.5 & $2012 / 05 / 25$ & 44.85249 & 11.59847 & Nanometrics Orion & Lennartz 1s 3D Light \\
OG003 & Sant'Agostino & 16.7 & $2012 / 05 / 25$ & 44.786163 & 11.38337 & Reftek 130 & Episensor \\
OG004 & Ficarolo (RO) & 17.6 & $2012 / 05 / 25$ & 44.952037 & 11.433883 & Reftek 130 & Lennartz 5s \\
OG005 & Poggio Renatico & 24.3 & $2012 / 05 / 25$ & 44.766983 & 11.48494 & Nanometrics Orion & Lennartz 1s 3D Light \\
OG006 & Vigarano Pieve & 22.8 & $2012 / 05 / 25$ & 44.861937 & 11.514676 & Nanometrics Orion Lennartz 1s 3D Light \\
OG007 & Aguscello & 35.6 & $2012 / 05 / 25$ & 44.806519 & 11.663715 & Nanometrics Orion Lennartz 1s 3D Light \\
OG008 & Mirabello & 18.1 & $2012 / 05 / 25$ & 44.812673 & 11.431863 & Nanometrics Orion Lennartz 1s 3D Light \\
OG009 & San Carlo & 16.9 & $2012 / 06 / 25$ & 44.804401 & 11.408932 & Reftek 130 & Episensor \\
\hline
\end{tabular}

Table 1. Detail of the OGS temporarty network

can be found in the OGS Archive System of Instrumental Seismology (OASIS; oasis.crs.inogs.it) [Priolo et al. 2011], under the network code ZR. Here, we provide a short overview of the sites:

OG001 was located East of Ferrara, in the basement of the new city hospital located at Cona.

OG002 was inside a warehouse of the Ferrara Municipality, in front of the Chemical Industry of Ferrara, on a floor made of a concrete slab. The building is quite large, and it has a rectangular shape. The sensor was at the base of a NSoriented wall.

OG003 was deployed on farmland near the town of Sant'Agostino, a few meters from a small sand-liquefaction boil (about 3-4-m wide) that occurred during the mainshock of May 20, 2012. This accelerometer was buried in sandy soil in a 50-cm-deep hole.

OG004 was deployed in Ficarolo village, in the garden of the building of a branch of the Law Courts. The Lennartz $5 \mathrm{~s}$ sensor was buried in sandy soil at a depth of about $70 \mathrm{~cm}$.

OG005 was located in Poggio Renatico, in the courtyard of a private house.

OG006 was located in a private box-car in Vigarano Pieve.

OG007 was in the utility room of a private house in Aguscello.

OG008 was in Mirabello on the ground of a box near to a free parking area of a restaurant, where several cracks in the ground were observed after the mainshock.

OG009 was deployed in the basement of the church of San Carlo, where diffuse liquefaction phenomena were induced by the mainshock. Here, the whole floor, which was a concrete slab in a ca. $10 \mathrm{~m} \times 10 \mathrm{~m}$ hall in the church basement, was uplifted by about $50 \mathrm{~cm}$ to $80 \mathrm{~cm}$, due to sand injection. As already indicated, this site replaced OG003, and it was set-up one month later than the others.

Unfortunately, there were some problems when the first dump of data was analysed, such that some data were lost or not usable (e.g., saturation for the largest events). However, this is not relevant for the aims of the present re- port, and will be considered in a later report.

The group of Potenza University took passive noise measurements at sites OG003, OG006 and OG008. Single station measurements were performed using the Tromino ${ }^{\circledR}$ instrument, while for the array measurements, the Geode 24-channel modular acquisition system by Geometrics was used, equipped with Geospace $4.5 \mathrm{~Hz}$ geophones.

Some tests were performed to verify the consistency of the noise measurements performed by the two different kinds of instrument. As a result, excellent agreement was found between the HVSRs calculated from the passive noise

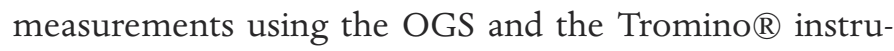
mentation in the frequency band of $0.3 \mathrm{~Hz}$ to $15 \mathrm{~Hz}$, of interest for this study.

\section{HVSR and ESAC results}

Figure 4 shows the HVSRs calculated from the single station measurements. The ratios were aligned along two hypothetical transects that run SW-NE (Transect 1: with stations OG003, OG005 [as a lateral extension], OG008, OG006) and SE-NW (Transect 2: OG001, OG007, OG002, OG006, OG004), as shown in Figure 3. Note that Transects 1 and 2 are orthogonal and normal, respectively, to the main geological structures. The HVSRs shows relatively good coherence; e.g., an evident, although spread, low frequency peak, at a frequency between $0.5 \mathrm{~Hz}$ to $1.5 \mathrm{~Hz}$. In some cases, this peak is sharper, as for OG002, OG006 and OG007, while for other sites, such as OG004 and OG008, it is much broader. The amplitude of these peaks is always weak, and the HVSR ranges from 2.0 to 4.2 .

Figure 5 and Table 2 give the vertical profiles of the shear-wave velocity (Vs) inverted for sites OG003, OG006 and OG008 through the ESAC method, from passive noise measurements of the array and with the additional constraint of the HVSR calculated from single station noise. The details of the array geometries are shown in Figure 6. The actual array length and the resulting investigation depth were, respectively: $345 \mathrm{~m}$ and $120 \mathrm{~m}$ for OG003; $330 \mathrm{~m}$ and $110 \mathrm{~m}$ for OG006; and $340 \mathrm{~m}$ and $120 \mathrm{~m}$ for OG008. In all 
OG004
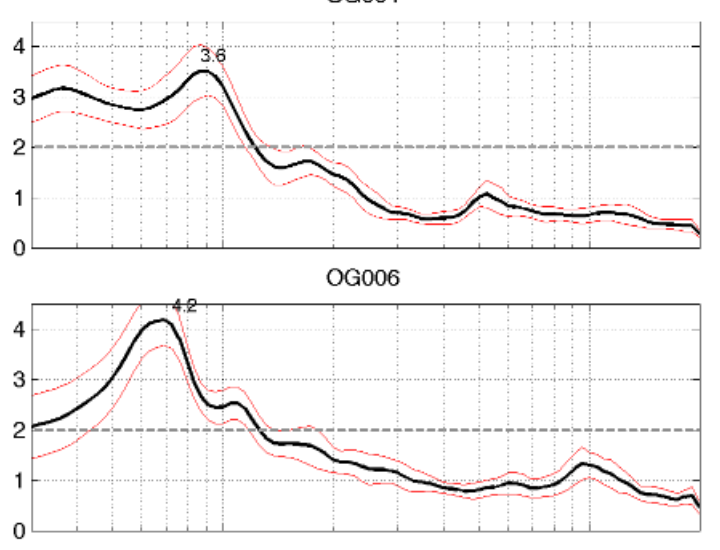

OG002

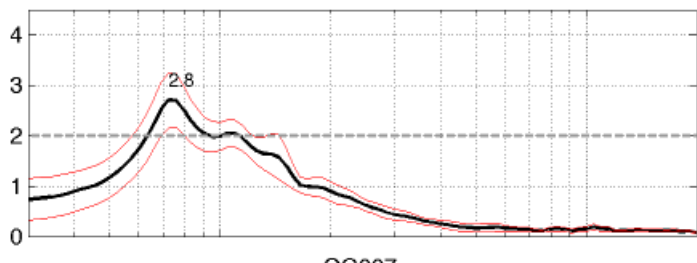

OG007
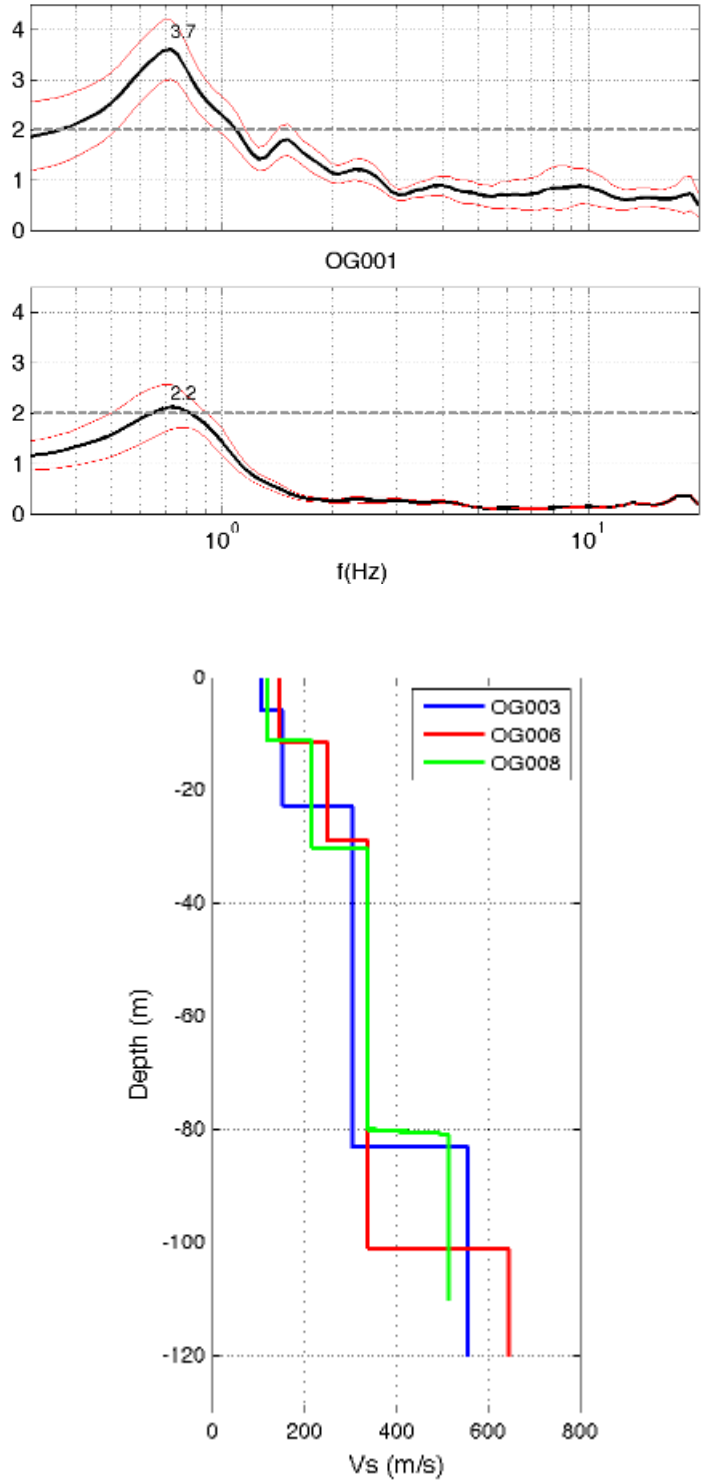

Figure 5. Vs estimation by the ESAC method at the OG003, OG006 and OG008 sites.
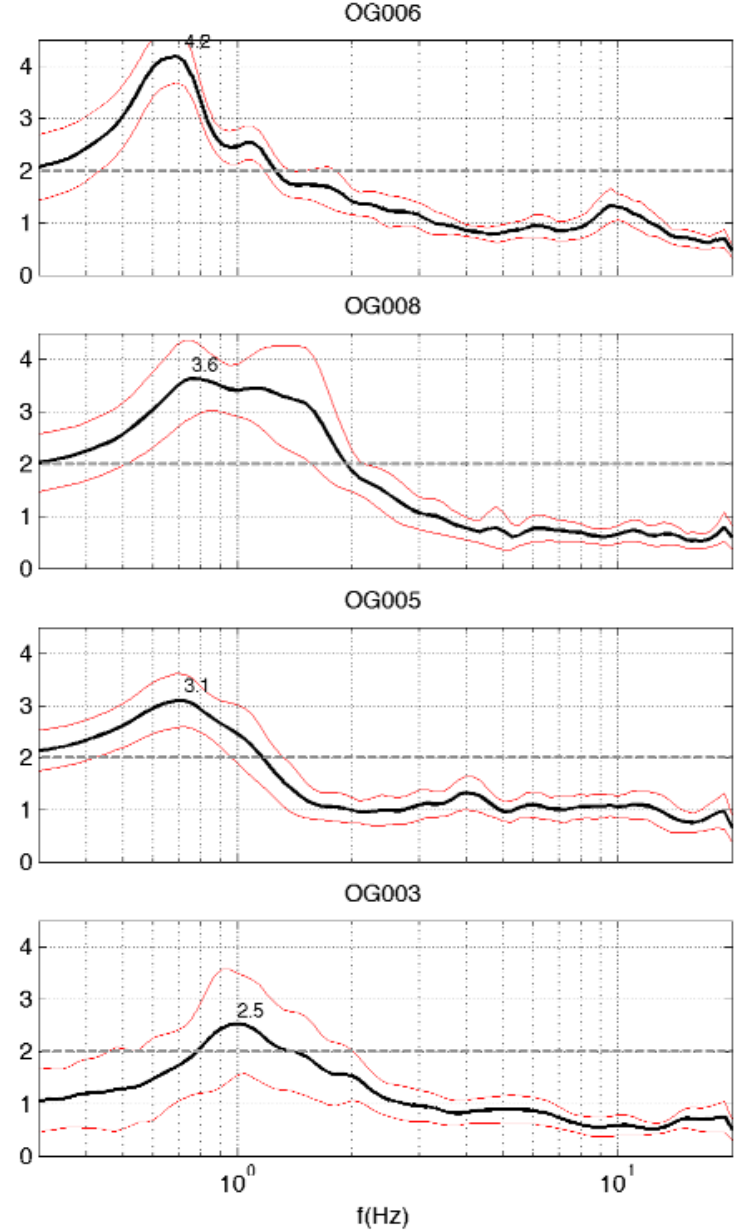

Figure 4. Single station seismic noise HVSRs estimated along the two transects shown in Figure 3. Transect 1 (right) runs in the SW-NE direction and includes stations OG003, OG005 (about $6 \mathrm{~km}$ out of line), OG008 and OG006. Transect 2 (left) runs in the SE-NW directions and includes stations OG001, OG007, OG002, OG006 and OG004. The H/V peak value is specified for each curve.

\begin{tabular}{|c|c|c|}
\hline Site & Depth (m) & $\mathrm{Vs}(\mathrm{m} / \mathrm{s})$ \\
\hline \multirow[t]{4}{*}{ OG003 } & $0.0-5.86$ & 106 \\
\hline & $5.86-22.76$ & 152 \\
\hline & $22.76-83.24$ & 305 \\
\hline & $>83.25$ & 556 \\
\hline \multirow[t]{4}{*}{ OG006 } & $0.0-11.5$ & 146 \\
\hline & $11.5-29.0$ & 250 \\
\hline & $29.0-101$ & 337 \\
\hline & $>101$ & 645 \\
\hline \multirow[t]{4}{*}{ OG008 } & $0.0-11.30$ & 120 \\
\hline & $11.30-30.20$ & 215 \\
\hline & $30.20-80.80$ & 337 \\
\hline & $>80.80$ & 515 \\
\hline
\end{tabular}

Table 2. Velocity and depth estimates using the extended spatial autocorrelation method at the OG003, OG006 and OG008 sites. 


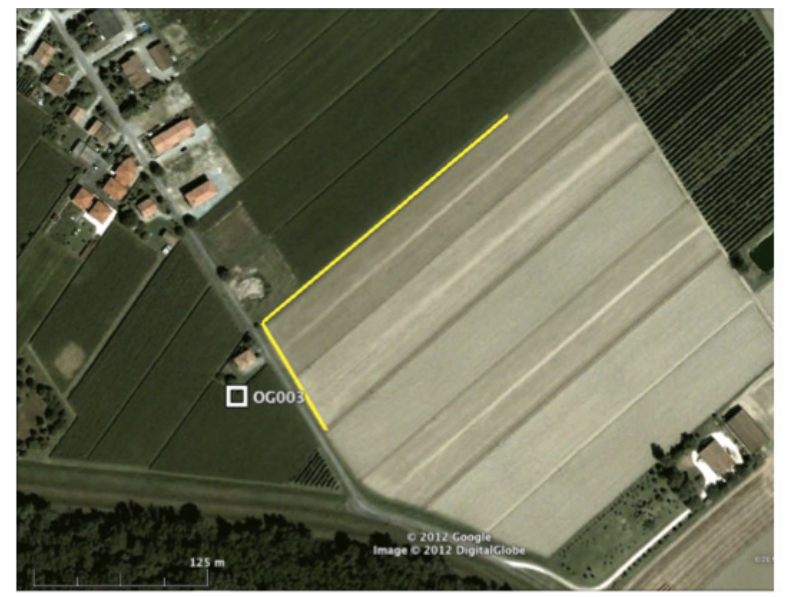

\begin{tabular}{|c|c|c|c|c|c|c|c|c|}
\hline \multicolumn{8}{|c|}{ Stations Coordinates } & $y$ \\
\hline Station 1 & 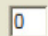 & $\sqrt{242}$ & Station 11 & 0 & 3 & Station 21 & 58. & 0 \\
\hline Station 2 & $\longdiv { 0 }$ & $\sqrt{182}$ & Station 12 & 0 & $\sqrt{1}$ & Station 22 & $\longdiv { 6 3 . }$ & 0 \\
\hline Station 3 & $\sqrt{0}$ & $\sqrt{132}$ & Station 13 & 0 & 0 & Station 23 & $\longdiv { 6 8 . }$ & 0 \\
\hline Station 4 & $\sqrt{0}$ & $\longdiv { 9 2 }$ & Station 14 & $\sqrt{0.9}$ & 0 & Station 24 & $\longdiv { 8 8 . }$ & 0 \\
\hline Station 5 & 0 & $\longdiv { 6 2 }$ & Station 15 & $\sqrt{2.9}$ & 0 & & & \\
\hline Station 6 & $\sqrt{0}$ & $\longdiv { 4 2 }$ & Station 16 & $\longdiv { 6 . 8 }$ & 0 & & & \\
\hline Station 7 & 0 & $\sqrt{27}$ & Station 17 & $\sqrt{11 .}$ & 0 & & & \\
\hline Station 8 & $\sqrt{0}$ & $\sqrt{17}$ & Station 18 & $\sqrt{19 .}$ & 0 & & & \\
\hline Station 9 & $\sqrt{0}$ & $\sqrt{12}$ & Station 19 & $\sqrt{29 .}$ & 0 & & & \\
\hline Station 10 & $\longdiv { 0 }$ & 7 & Station 20 & $\sqrt{49 .}$ & 0 & OGOC & & \\
\hline
\end{tabular}

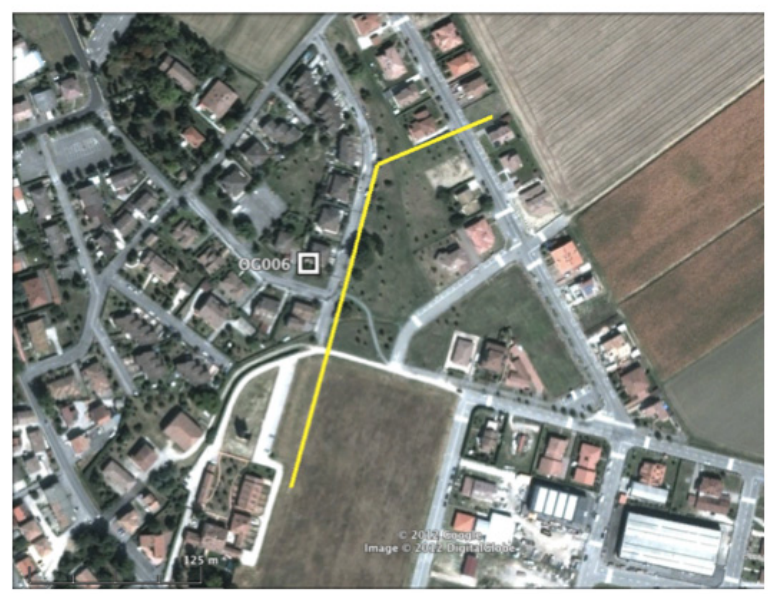

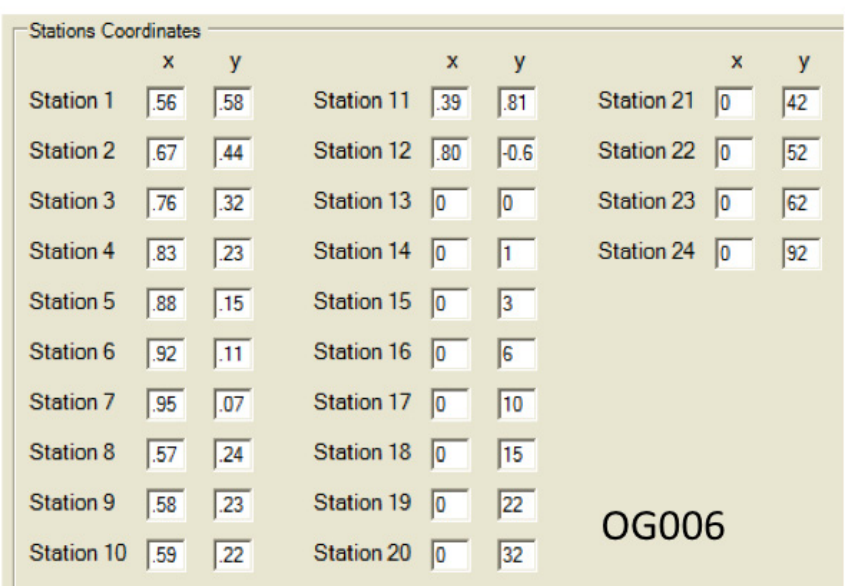

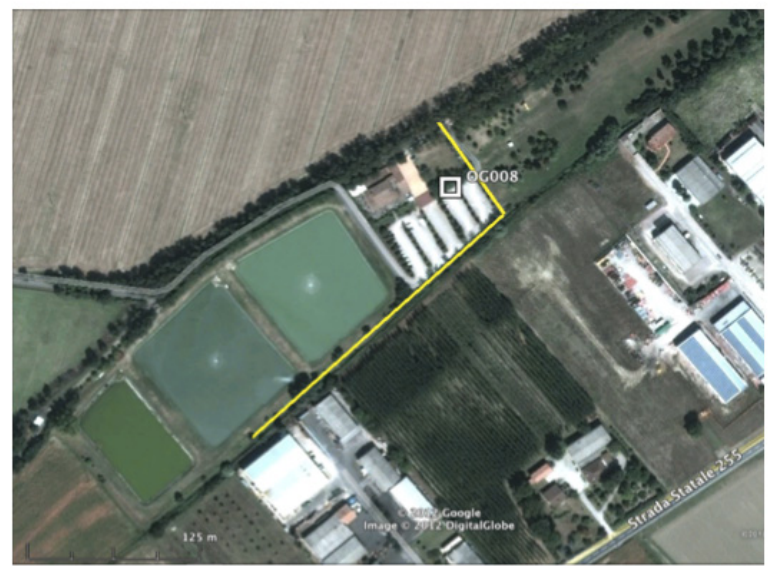

\begin{tabular}{|c|c|c|c|c|c|c|c|c|}
\hline \multicolumn{9}{|c|}{ Stations Coordinates } \\
\hline & $\mathrm{x}$ & y & & $x$ & y & & $\mathrm{x}$ & y \\
\hline Station 1 & $\longdiv { 0 }$ & $\sqrt{250}$ & Station 11 & 10 & 3 & Station 21 & $\sqrt{41 .}$ & -4.7 \\
\hline Station 2 & 0 & $\sqrt{190}$ & Station 12 & 0 & 1 & Station 22 & $\sqrt{51 .}$ & -5.9 \\
\hline Station 3 & $\longdiv { 0 }$ & $\sqrt{140}$ & Station 13 & $\sqrt{0}$ & $\longdiv { 0 }$ & Station 23 & 66. & -7.6 \\
\hline Station 4 & 0 & $\sqrt{100}$ & Station 14 & $\sqrt{0.9}$ & $\sqrt{-0.1}$ & Station 24 & 91. & -10. \\
\hline Station 5 & $\sqrt{0}$ & $\sqrt{70}$ & Station 15 & $\sqrt{2.9}$ & $\sqrt{-0.3}$ & & & \\
\hline Station 6 & 10 & 50 & Station 16 & $\sqrt{5.9}$ & $\sqrt{-0.6}$ & & & \\
\hline Station 7 & 0 & $\sqrt{30}$ & Station 17 & $\longdiv { 9 . 9 }$ & $\sqrt{-1.1}$ & & & \\
\hline Station 8 & $\sqrt{0}$ & $\sqrt{17}$ & Station 18 & $\sqrt{14 .}$ & $\sqrt{-1.7}$ & & & \\
\hline Station 9 & $\sqrt{0}$ & $\sqrt{12}$ & Station 19 & $\sqrt{21 .}$ & $\sqrt{-2.5}$ & & & \\
\hline Station 10 & 0 & 7 & Station 20 & $\sqrt{31 .}$ & $\sqrt{-3.6}$ & & & \\
\hline
\end{tabular}

Figure 6. Array geometry (yellow lines) of the ESAC surveys performed at the OG003, OG006 and OG008 sites. For each site, a map and a list of the geophone coordinates are shown. The location of the temporary station is indicated by a white square in each map. The array geometry consists of two nearly orthogonal branches. The array length specified in the text is the total length of the two branches.

cases, a four-layer model was used in the inversion. Sites OG006 and OG008 features relatively similar structures: the Vs started with very low values at the surface, which ranges from $120 \mathrm{~m} / \mathrm{s}$ to $150 \mathrm{~m} / \mathrm{s}$ in the shallow-most $10 \mathrm{~m}$, and increases with depth, with values of about $215 \mathrm{~m} / \mathrm{s}$ to $250 \mathrm{~m} / \mathrm{s}$ at a depth of ca. $20 \mathrm{~m}$ to $30 \mathrm{~m}$, and then of $337 \mathrm{~m} / \mathrm{s}$ for a further ca. $50 \mathrm{~m}$. While the Vs appears to increase uniformly for OG008 also at greater depths, with a value of $515 \mathrm{~m} / \mathrm{s}$, a velocity contrast is imaged for site OG006 at a depth of $95 \mathrm{~m}$ to $110 \mathrm{~m}$, where the velocity jumps to $645 \mathrm{~m} / \mathrm{s}$. The HVSRs of those two sites (Figure 4) conform very well to this interpretation, with OG008 showing a much broader and smoother peak than that of OG006.

Site OG003 has even lower velocity values than the previous sites. We note here that some particular events of sand liquefaction occurred here. The Vs ranges from ca. $100 \mathrm{~m} / \mathrm{s}$ at the surface, for the shallow-most $6 \mathrm{~m}$, and progressively increases at about $150 \mathrm{~m} / \mathrm{s}$ from $6 \mathrm{~m}$ to $22 \mathrm{~m}$, and $305 \mathrm{~m} / \mathrm{s}$ from $22 \mathrm{~m}$ to $83 \mathrm{~m}$. Again, relatively weak contrast is seen at $80 \mathrm{~m}$ to $90 \mathrm{~m}$ of depth, where the Vs reaches $550 \mathrm{~m} / \mathrm{s}$. 


\section{Discussion and conclusions}

All of the eight sites of the OGS temporary network analyzed in this study features common HVSR characteristics; i.e., a weak and broad peak of fundamental resonant frequency in the low frequency band from $0.5 \mathrm{~Hz}$ to $1.5 \mathrm{~Hz}$. The ESAC investigations performed at three sites shows that this peak was caused by a weak $S$-velocity contrast at depth of ca. $80 \mathrm{~m}$ to $100 \mathrm{~m}$. Above, the S-velocity progressively increases with depth, starting from very low values of about $100 \mathrm{~m} / \mathrm{s}$ to $150 \mathrm{~m} / \mathrm{s}$ at the surface, to $300 \mathrm{~m} / \mathrm{s}$ to $340 \mathrm{~m} / \mathrm{s}$ at a depth of $80 \mathrm{~m}$ to $100 \mathrm{~m}$. Beneath that depth and down to the investigation depth of about $110 \mathrm{~m}$ to $120 \mathrm{~m}$, the $\mathrm{S}$-velocity settles at $500 \mathrm{~m} / \mathrm{s}$ to $550 \mathrm{~m} / \mathrm{s}$, although site OG006 has a higher velocity, of $650 \mathrm{~m} / \mathrm{s}$. Coherently, the sharpest HVSR curve is estimated at this site.

The very low velocities at the surface corresponds to cohesionless soils that are characterized by very low shear-modulus values, such as the sandy and silty-sandy soils that are commonly found in that area. This study provides just the preliminary results: for instance, it does not provide the actual spectral amplification of the investigated sites. More thorough data will follow from the analysis of the recorded earthquakes.

Finally, at site OG0004, which is the northern-most site of Transect 2 (Figure 2), the HVSR features a very broad, low-frequency lobe, with two distinct peaks at $0.3 \mathrm{~Hz}$ to 0.4 $\mathrm{Hz}$ and at $0.9 \mathrm{~Hz}$ (Figure 4). While the latter is well correlated to that of the other transect stations, the peak at the lowest frequency might indicate the presence of a deeper, structural S-velocity contrast. This hypothesis agrees relatively well with the thickening of the sediments previously documented in the area of Ficarolo (Figure 2), where station OG004 was located.

Acknowledgements. We thank Elisa Zambonelli of the National Department of Civil Protection, and Lucia Margheriti of the Istituto Nazionale di Geofisica e Vulcanologia (INGV), who gave us many important pieces of information and helped us to keep tightly coordinated with the interventions of their Institutes.

\section{References}

CNR-PFG (Progetto Finalizzato Geodinamica) (1991). Synthetic structural-kinematic map of Italy. Structural model of Italy, Sheet n. 5, S.EL.CA., Firenze.

Dolce, M., M. Nicoletti, A. Ammirati, R. Bianconi, L. Filippi, A. Gorini, S. Marcucci, F. Palma, E. Zambonelli, G. Lavecchia, R. de Nardis, F. Brozzetti, P. Boncio, D. Cirillo, A. Romano, G. Costa, A. Gallo, L. Tiberi, G. Zoppé, P. Suhadolc, F. Ponziani and A. Formica (2012a). The Emilia Thrust Earthquake of 20 May 2012 (Northern Italy): Strong Motion and Geological Observations - Report 1, National Civil Protection Department (DPC); http: / / www.protezionecivile.gov.it/jcms / it/ ran.wp

Dolce, M., M. Nicoletti, A. Ammirati, R. Bianconi, L. Filippi,
A. Gorini, S. Marcucci, F. Palma, E. Zambonelli, G. Lavecchia, R. de Nardis, F. Brozzetti, P.Boncio, D. Cirillo, A. Romano, G. Costa, A. Gallo, L. Tiberi, G. Zoppé, P. Suhadolc, F. Ponziani and A. Formica (2012b). The Ferrara Arc Thrust Earthquakes of May-June 2012 (Northern Italy): Strong-Motion and Geological Observations Report II, National Civil Protection Department (DPC); http: / / www.protezionecivile.gov.it/jcms/it/ ran.wp

Moretti, M., et al. (2012). Rapid response to the earthquake emergency of May 2012 in the Po Plain, northern Italy, Annals of Geophysics, 55 (4); doi:10.4401/ag-6152.

Ohori, M., A. Nobata and K. Wakamatsu (2002). A comparison of ESAC and FK methods of estimating phase velocity using arbitrarily shaped microtremor arrays, B. Seismol. Soc. Am., 92, 2323-2332.

Okada, H., K. Matsushima and E. Hidaka (1987). Comparison of spatial autocorrelation method and frequencywavenumber spectral method of estimating the phase velocity of Rayleigh waves in long-period microtremors, Geophys. B. Hokkaido Univ. 49, 53-62 (in Japanese with English abstract).

Papathanassiou, G., R. Caputo and D. Rapti-Caputo (2012). Liquefaction phenomena along the palaeo-Reno River caused by the May 20, 2012 Emilia (northern Italy) earthquake, Annals of Geophysics, 55 (4); doi:10.4401/ag-6147.

Pieri, M., and G. Groppi (1981). Subsurface geological structure of the Po Plain, Italy. Consiglio Nazionale delle Ricerche, Progetto finalizzato Geodinamica, Sottoprogetto Modello Strutturale, Roma, 414, 13 pp.

Priolo, E., G. Laurenzano, C. Barnaba, P. Bernardi, L. Moratto and A. Spinelli (2011). OASIS - The OGS Archive System of Instrumental Seismology, In: M. Mucciarelli (ed.), Tecniche Speditive per la Stima dell'Amplificazione Simica. Studi teorici ed applicazioni professionali, Roma, Aracne editrice, $445 \mathrm{pp}$.

Regione Emilia-Romagna and ENI-AGIP (1998). Riserve idriche sotterranee della Regione Emilia-Romagna, edited by G. Di Dio, Firenze, S.El.Ca., 120 pp.

Toscani, G., P. Burrato, D. Di Bucci, S. Seno and G. Valensise (2009). Plio-Quaternary tectonic evolution of the northern Apennines thrust fronts (Bologna-Ferrara section, Italy): seismotectonic implications, B. Soc. Geol. Ital., 128, 605-613.

\footnotetext{
${ }^{\star}$ Corresponding author: Enrico Priolo, Istituto Nazionale di Oceanografia e di Geofisica Sperimentale (OGS), Centro di Ricerche Sismologiche (CRS), Udine and Trieste, Italy; email: epriolo@ogs.trieste.it.
}

(C) 2012 by the Istituto Nazionale di Geofisica e Vulcanologia. All rights reserved. 